\title{
Validity of Intraoral surgical approach for enucleation of large plunging sublingual dermoid cysts
}

\author{
Original Hamed Mohamed Gad and Abdullah A. Hammuda \\ Article
Department of Oral and Maxillofacial Surgery, Faculty of Dentistry, Minia University, Minia, Egypt

\begin{abstract}
Background: The intraoral approach for surgical enucleation may be used for small cysts with a diameter of $6 \mathrm{~cm}$ and less, however larger lesions i.e. more than $6 \mathrm{~cm}$ in diameter which are extending below the mylohyoid muscle and involving the submental and submandibular spaces require an extra oral incision.

Aim of the study: To evaluate the validity of the intraoral surgical approach for enucleation of large plunging sublingual dermoid cysts which extended below the mylohyoid muscles.

Patients and methods: 7 patients (15 to 33 years old) had been suffered from sublingual dermoid cysts. They were presented with complaints of slowly growing painless mass in the floor of the mouth, difficulties in chewing and swallowing solid foods. All selected cases included cysts diameters $\geq 6 \mathrm{~cm}$. All cases were operated under general anesthesia and subjected to complete enucleation through the intraoral approach. Pain, swelling, trismus, salivary flow and lingual nerve injuries were evaluated immediately, 7 days and 30 days after surgery.

Results: a significant reduction of pain after 30 days $p<0.05$ and no statistically significant changes between immediate and after 30 days according to trismus assessment. A statistically significant reduction in swelling between immediate and after 30 days. No change in Salivary flow or affection and nerve injuries were reported through the follow up period. no recurrences of all cystic lesions were detected 1 year postoperative follow-up.

Conclusion: The intraoral sublingual approach could be used safely to access and excise large plunging sublingual dermoid cysts regarding clinical outcomes.
\end{abstract}

Key Words: Dermoid cyst, Floor of mouth, Intraoral approach, Surgical treatment.

Received: 16 May 2020, Accepted: 14 July 2020.

Corresponding Author: Hamed Mohamed Gad, Department of Oral and Maxillofacial Surgery, Faculty of Dentistry, Minia University, Cairo, Egypt, Tel.: +2045 3381047, Mobile:+201006949485, E-mail: drhamed_drhamed@yahoo.com.

ISSN: 2090-097X, April 2020, Vol. 11, No. 2

\section{INTRODUCTION}

Dermoid and epidermoid cysts are extremely rare developmental cysts of a benign nature, which may occur anywhere in the body, however mainly it occurs in the ovary and scrotal areas ${ }^{[1,2]}$.

Dermoid cysts of the head and neck are constituting $7 \%$ of total dermoid cysts occurring in the body. The floor of the mouth is one of the most frequently affected areas ${ }^{[3,4]}$. Anatomical localization of the dermoid cysts of the floor of the mouth are classified into four types: Sublingual (above the mylohyoid muscle, $52.5 \%$ ), submental (below the mylohyoid muscle, $40.4 \%)$, sublingual - submental $(11.6 \%)$ and lateral (submandibular, $18.2 \%)^{[5]}$.

Dermoid cysts are congenital but they can be presented in the second or third decade of life as painless slowly growing masses that may reach a large size and involve more than one anatomical area. In such a case, swelling in the floor of the mouth can occasionally cause serious problems of dysphagia, dysphonia, and dyspnea, or the patient presents with a double $\operatorname{chin}^{[6-7]}$.

Complete surgical enucleation is the treatment of choice for dermoid cysts. It was documented that; the approach can be either intraoral or extra-oral, depending on the localization and size of the intraoral dermoid cyst. An intraoral incision may be used for small cysts with a diameter of $6 \mathrm{~cm}$ and less, but larger lesions i.e. more than $6 \mathrm{~cm}$ in diameter which extending below the mylohyoid muscle and involving the submental and submandibular spaces require an extra-oral incision $^{[8,9]}$. Furthermore; the current study aimed to evaluate the validity of the intraoral surgical approach for enucleation of large plunging sublingual dermoid cysts which extended below the mylohyoid muscles.

\section{PATIENTS AND METHODS}

Seven patients 5 females and 2 males, ages ranged from 15 to 33 years were included in the current study. They had been diagnosed at the Maxillofacial Surgery Department 
of Minia University Dental Hospital (MUDH) from 2015 to 2019 .

The age, gender, symptoms, clinical examination, and localization were recorded. The patients included in the current study were suffered from intraoral and sub mental swellings with its diameters equal to or more than $6 \mathrm{~cm}$ (Table 1). All patients were suffered from difficulty in chewing foods, swallowing, or speech difficulties due to impaired movements of the tongue of these patients with different degrees (Figure 1). All patients were examined radio-graphically by multi slice computerized tomography MSCT scan which revealed the cysts appear as moderately thick-walled, uni-locular masses filled with a homogeneous, hypo-attenuating fluid substance. Needle aspiration was performed for all lesions to confirm the initial diagnosis. Where these aspirations were thick viscous yellow color cheesy material (Figure 2).

Table 1: Average size of lesions for all cases:

\begin{tabular}{lll}
\hline Case & Diameter & \\
\hline Case 1 & $6.4 \mathrm{~cm}$ & \\
Case 2 & $6.5 \mathrm{~cm}$ & \\
Case 3 & $7 \mathrm{~cm}$ & Mean 6.73 \\
Case 4 & $6.2 \mathrm{~cm}$ & \\
Case 5 & $7.5 \mathrm{~cm}$ & \\
Case 6 & $7 \mathrm{~cm}$ & \\
Case 7 & $6.5 \mathrm{~cm}$ & \\
\hline
\end{tabular}

\section{Preoperative preparation:}

Laboratory investigations, in favor of revise of complete blood picture, coagulation profile (prothrombin time (PT), partial thromboplastin time (PPT), bleeding time (BT)), random blood glucose level, liver and renal function tests.

Surgical procedure: All lesions were surgically enucleated under general anesthesia with nasotracheal intubation. Draping and scraping of all patients were achieved according to the standard maxillofacial surgery protocol. Preoperative injectable antibiotics (Unasyn $1.5 \mathrm{gm} \mathrm{vial*}$ after hypersensitivity tests and Dexamethasone sodium phosphate**.

* Ampicillin /sulbactam, syrup, PFIZER, Egypt).

** (Dexamethasone sodium phosphate $8 \mathrm{mg} / 2 \mathrm{ml}$ (Pharm Ind. Alexandria, Egypt).

Submucosal incision sites were infiltrated with 5 cc 1:100000 adrenaline solution. Access to the lesions were performed through an intraoral sublingual incisions at the junction of the ventral surface of the tongue and the floor of the mouth to enucleate these cysts. Special cautious during blunt dissection along the hyoglossus and genioglossus muscles to prevent injuries of both submandibular and sublingual salivary gland ducts. Superior, medial and lateral surfaces of the cyst
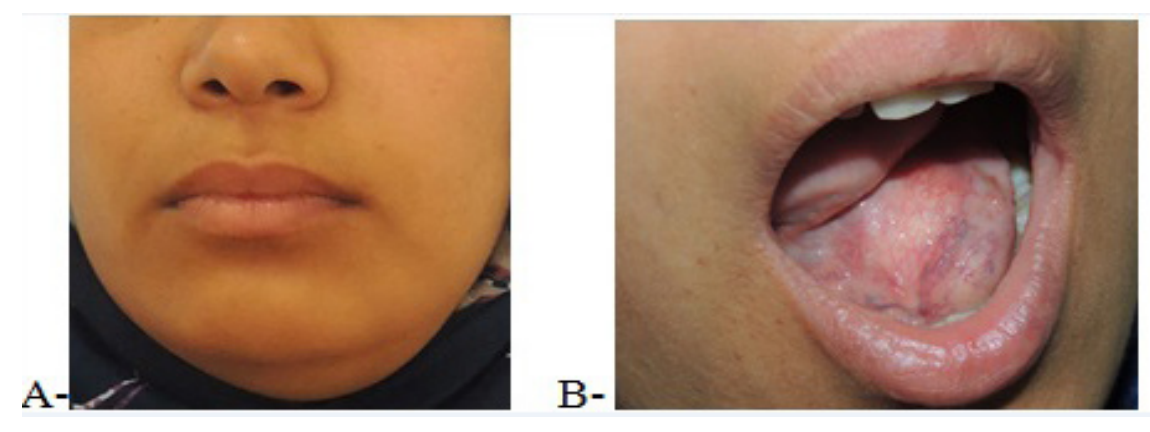

Figure 1: (A) Swelling in the submental region, (B) Raised floor of the mouth.

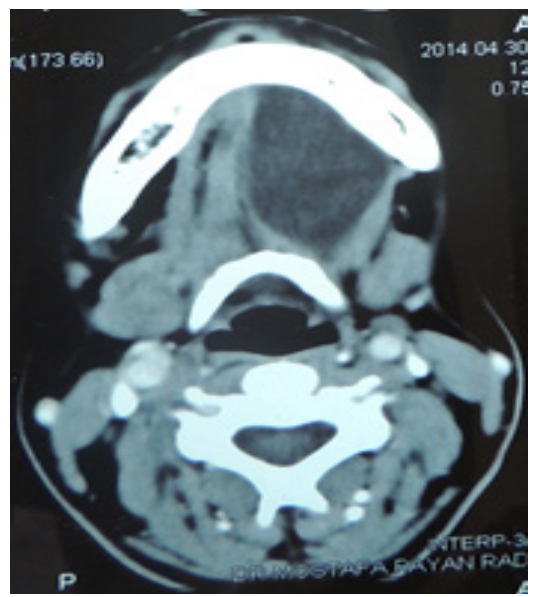

Figure 2: Axial CT scan showing the extension of the cyst to supra-hyoid region inferior to genioglossus. 
were completely exposed, then evaluation of partial caudal herniation through the mylohyoid muscle. A combination of sharp and blunt dissection was used to free the cyst with traction and counter-traction. Blunt dissection was carried out around the lesion and cystic enucleation was performed. During enucleation, the cyst wall in some cases was perforated releasing cheese-like exudates (Figures 3 and 4).
After complete excision of the cysts, each field was washed out using normal saline. The wounds were closed by deep and superficial sutures using vicryl 4 / 0 (Vicryl*. During suturing of the mucosa of the floor of the mouth, attention to the course of the Wharton's ducts were considered to avoid any lacerations or injuries. All excised lesions were preserved in formalin $10 \%$ and referred for histopathological examination to confirm the initial diagnosis (Figure 5).
(A)

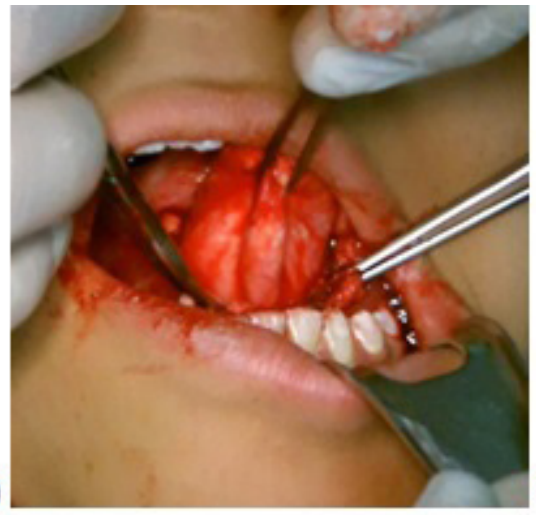

(B)

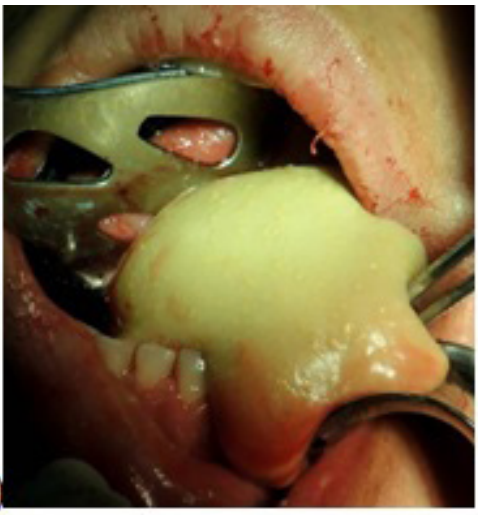

Figure 3: (A) Intraoperative view of dissection. (B)intraoperative image showing granular cheesy leakage of content:

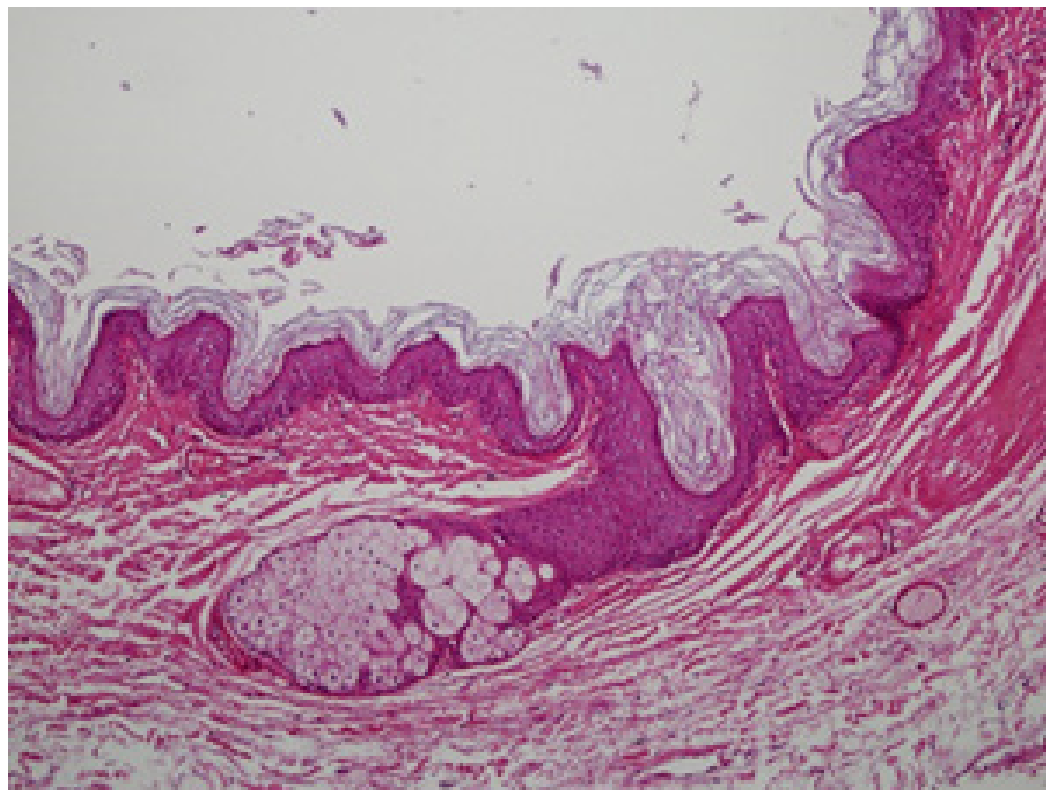

Figure 4: Microscopic examination revealed a cystic structure lined with squamous epithelium and its lumen containing keratinous material. Sebaceous gland connected with squamous epithelium in one area $(\mathrm{HE} \times 100)$ 


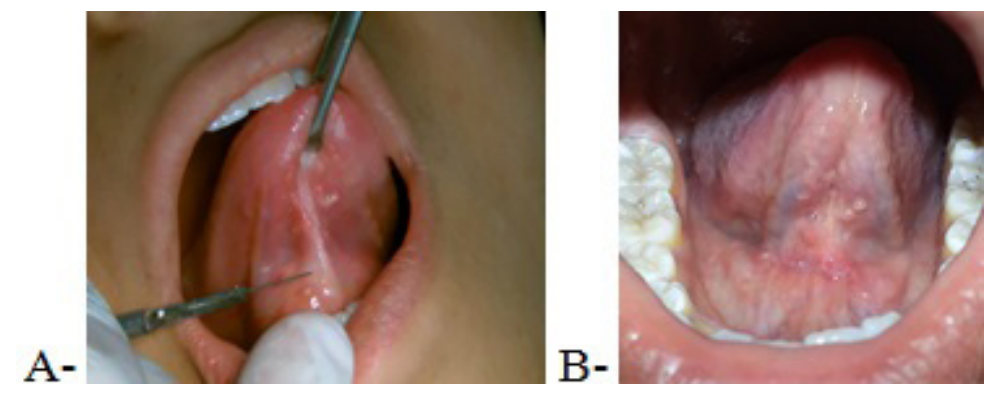

Figure 5: (A) preoperative and 30 days Post-operative photographic view for one case (B).

Postoperatively, all patients received injectable antibiotics twice per day for 5 days. (Unasyn $1.5 \mathrm{gm}$ vial, Dexamethasone sodium phosphate $8 \mathrm{mg} / 2 \mathrm{ml}$ and anti inflammatory and analgesics (Brufen 400 tablet**. Patients instructed for soft diet and regular oral hygiene for one week At $7^{\text {th }}$ day postoperatively, the superficial sutures were removed, the patency of Wharton's duct was evaluated by an immediate escape of saliva from it. Postoperatively the cases were under regular follow up for 7 and 30 days for pain, trismus, swelling, salivary flow and lingual nerve injuries assessment late follow up after one year for evaluation of cystic recurrences. Spain).

*polyglycolic acid synthetic absorbable, Barcelona,

**ibuprofen EL-kahera, Egypt).

\section{Assess ment parameters:}

\section{Pain assessment:}

All patients were evaluated at early postoperative follow up ( $7^{\text {th }}$ day) and late postoperative (30 days) according to the following pain scoring system in (Table 2).

Table 2: Pain assessment scoring:

\begin{tabular}{llc}
\hline Assessment & Description & Score \\
\hline No pain & Feels well & 1 \\
Slight pain & $\begin{array}{l}\text { If distracted, does not feel } \\
\text { the pain }\end{array}$ & 2 \\
Mild pain & $\begin{array}{l}\text { Feel pain even concentrating } \\
\text { on some activities }\end{array}$ & 3 \\
Moderate & $\begin{array}{l}\text { Very disturbed but can } \\
\text { continue in normal activities }\end{array}$ & 4 \\
Severe pain & $\begin{array}{l}\text { Forced to abandon the } \\
\text { normal activities }\end{array}$ & 5 \\
Extremely severe pain & $\begin{array}{l}\text { Abandon any activity and } \\
\text { need to lie down }\end{array}$ & 6 \\
\hline
\end{tabular}

\section{Trismus assessment:}

Interincisal mouth openings were measured in millimeters $(\mathrm{mm})$, Preoperative, at $7^{\text {th }}$ and $30^{\text {th }}$ day postoperative.

\section{Swelling assessment:}

Evaluation of sublingual and extra-oral swellings was recorded according to the following score in (Table 3):

Table 3: Pain assessment scoring:

\begin{tabular}{llc}
\hline Assessment & Description & Score \\
\hline No swelling & $\begin{array}{l}\text { The patient does not detect any } \\
\text { slight swelling. }\end{array}$ & 1 \\
Mild swelling & $\begin{array}{l}\text { The swelling is noticeable but } \\
\text { not interfere with mastication } \\
\text { and swallowing. }\end{array}$ & 2 \\
Moderate swelling & $\begin{array}{l}\text { The swelling is evident and } \\
\text { interferes with mastication. }\end{array}$ & 3 \\
Severe swelling & $\begin{array}{l}\text { The swelling is marked; } \\
\text { mastication is hindered but no } \\
\text { limitation in MO. }\end{array}$ \\
\hline
\end{tabular}

\section{Salivary flow:}

The salivary flow was evaluated according to the following score in (Table 4):

Table 4: Salivary flow assessment score:

\begin{tabular}{llc}
\hline Assessment & Description & Score \\
\hline $\begin{array}{l}\text { No salivary } \\
\text { affection }\end{array}$ & $\begin{array}{l}\text { The patient does not detect a } \\
\text { change in salivary flow. }\end{array}$ & 1 \\
$\begin{array}{l}\text { Mild salivary } \\
\text { affection }\end{array}$ & $\begin{array}{l}\text { Mild pain and swelling is } \\
\text { evident in the affected gland. }\end{array}$ & 2 \\
$\begin{array}{l}\text { Moderate salivary } \\
\text { affection }\end{array}$ & $\begin{array}{l}\text { Moderates Pain and swelling is } \\
\text { evident in the affected gland. }\end{array}$ & 3 \\
$\begin{array}{l}\text { Sever salivary } \\
\text { affection }\end{array}$ & $\begin{array}{l}\text { Severe pain and swelling is } \\
\text { evident in the affected gland. }\end{array}$ & 4 \\
\hline
\end{tabular}




\section{Lingual nerve injuries assessment:}

Evaluation of lingual nerve affection was introduced according to Nerve affection scoring Brushstroke directional sensation with camel hair brush through horizontal, vertical, and rotational stimulating movement $\left(\right.$ Table 5) ${ }^{[10]}$

Table 5: Lingual Nerve scoring:

\begin{tabular}{lllll}
\hline \multicolumn{1}{l}{ Assessment } & \multicolumn{2}{l}{ Description } & Score \\
\hline No nerve affection & $\begin{array}{l}\text { Means recognized } \\
\text { movements). }\end{array}$ & all & 1 \\
Mild & nerve & $\begin{array}{l}\text { Means recognized } \\
\text { directions. }\end{array}$ & two & 2 \\
$\begin{array}{l}\text { affection } \\
\begin{array}{l}\text { Moderate } \\
\text { affection }\end{array}\end{array}$ & nerve & $\begin{array}{l}\text { Means recognized only one } \\
\text { direction. }\end{array}$ & 3 \\
$\begin{array}{l}\text { Sever } \\
\text { affection }\end{array}$ & nerve & Means recognized not at all. & 4 \\
\hline
\end{tabular}

\section{Statistical analysis:}

Recorded data were analyzed using the statistical package for social sciences, version 20.0 (SPSS Inc., Chicago, Illinois, USA). Quantitative data were expressed as mean \pm standard deviation (SD). Qualitative data were expressed as frequency and percentage. The confidence interval was set to $95 \%$ and the margin of error accepted was set to $5 \%$. A paired sample t-test of significance was used when comparing between related sample. Chi square $\left(\mathrm{x}^{2}\right)$ tests of significance were used to compare proportions between qualitative parameters.

\section{RESULTS}

Seven patients were included in this current study with an age range between 15 to 33 years (mean $24.7 \mathrm{sd} 4.2$ ), 5 females and 2 males. all cystic lesions were enucleated through an intraoral surgical approach. pain, trismus, swelling, salivary flow, lingual nerve affection were assessed at immediate, 7 days and 30 days postoperative, which reveal no clinical affection of these parameters meanwhile; no recurrences of all cystic lesions were detected 1 year postoperative follow-up (Figure 5).

\section{Statistical analysis:}

1. Pain: Showed a significant reduction of pain after 30 days $p<0.05$ (Table 6)

2. Trismus: It declared no statistically significant changes between immediate and after 30 days according to trismus assessment (Table 7).

3. Swelling: Showed a statistically significant reduction in between immediate and after 30 days (Table 8).

4. Salivary flow affection and nerve injuries: Showed no change or affection (Tables 9 and 10).

Table 6: The extent of the difference over the periods thorough pain assessment:

\begin{tabular}{llllll}
\hline Pain assessment & Range & Mean $\pm \mathrm{SD}$ & Mean Diff. & Paired t-test & $p$-value \\
\hline Immediate & $1-4$ & $2.29 \pm 0.95$ & & & \\
After 7 days & $1-3$ & $2.30 \pm 0.69$ & -0.150 & 1.000 & 0.356 \\
After 30 days & $1-2$ & $1.29 \pm 0.49$ & -1.000 & 4.583 & $0.004^{*}$ \\
\hline
\end{tabular}

$p$-value $>0.05 \mathrm{NS} ;{ }^{*} p$-value $<0.05 \mathrm{~S}$

Table 7: The extent of the difference over the periods through trismus assessment:

\begin{tabular}{llllll}
\hline Trismus assessment & Range & Mean \pm SD & Mean Diff. & Paired t-test & $p$-value \\
\hline Pre-operation & $34-37$ & $36.30 \pm 36.86$ & & & \\
After 3 days & $35-39$ & $36.86 \pm 1.35$ & 0.71 & -0.918 & 0.394 \\
After 7 days & $35-38$ & $36.43 \pm 0.98$ & 0.29 & -0.420 & 0.689 \\
After 30 days & $35-38$ & $36.71 \pm 1.11$ & 0.57 & -0.834 & 0.436 \\
\hline
\end{tabular}

Table 8: The extent of the difference over the periods through swelling:

\begin{tabular}{|c|c|c|c|c|c|}
\hline Swilling & Range & Mean \pm SD & Mean Diff. & Paired t-test & $p$-value \\
\hline Immediate postoperative & $1-3$ & $2.0 \pm 0.82$ & & & \\
\hline After 7 days postoperative & $1-2$ & $1.57 \pm 0.53$ & -0.43 & 2.121 & 0.078 \\
\hline $\begin{array}{l}\text { After } \quad 30 \\
\text { postoperative }\end{array}$ & $1-1$ & $1.0 \pm 0.0$ & -1.00 & 3.240 & $0.018 *$ \\
\hline
\end{tabular}


Table 9: The extent of the difference over the periods through salivary affection. Agreement and disagreement can't be calculated because all data of one parameter are no affection:

\begin{tabular}{lllll}
\hline Salivary Affection & No & Mild & Moderate & Sever \\
\hline Immediate & $7(100 \%)$ & $0(0 \%)$ & $0(0 \%)$ & $0(0 \%)$ \\
7 days postoperative & $7(100 \%)$ & $0(0 \%)$ & $0(0 \%)$ & $0(0 \%)$ \\
30 days postoperative & $7(100 \%)$ & $0(0 \%)$ & $0(0 \%)$ & $0(0 \%)$ \\
Chi-square test & & & 0.000 & 1.000 \\
$p$-value & & & \\
\hline
\end{tabular}

Table 10: The extent of the difference over the periods of lingual nerve affection:

\begin{tabular}{lllll}
\hline Lingual nerve & No & Mild & Moderate & Sever \\
\hline Immediate & $7(100 \%)$ & $0(0 \%)$ & $0(0 \%)$ & $0(0 \%)$ \\
7 days postoperative & $7(100 \%)$ & $0(0 \%)$ & $0(0 \%)$ & $0(0 \%)$ \\
30 days postoperative & $7(100 \%)$ & $0(0 \%)$ & $0(0 \%)$ & $0(0 \%)$ \\
Chi-square test & & & 0.000 & 1.000 \\
$p$-value & & & \\
\hline
\end{tabular}

\section{DISCUSSION}

The differential diagnosis of sublingual lesions included infections, ranula, salivary gland tumor, lymphatic malformation as cystic hygroma, heterotopic gastrointestinal cyst and duplication foregut cyst. For this reason, clinical examination and conventional radiography are not sufficient for diagnosis ${ }^{[11,12]}$.

In this current study, all cases were diagnosed by clinical ad computed tomography examinations followed by fine needle aspiration. These aspirates contents of a cheesy, keratinous like substances which were considered in initial diagnosis that excluded infections, salivary pathology, or vascular lesions.

Furthermore, all enucleated lesions were subjected to histopathologic examination that confirms the previous initial diagnosis. The histopathologic features of dermoid cysts are characteristic. The lining of the cysts was composed of orthokeratinized squamous epithelium with a prominent granular layer and a cystic capsule composed of dense connective tissue. However, these cysts usually presented with thin walls. The existence of cutaneous adnexa is considered the main histological difference with epidermoid cysts ${ }^{[13-16]}$. This finding was consistent with the current study observations.

Surgical enucleation is the treatment of choice for sublingual and submandibular/submental benign cystic lesions. It was recommended in the pieces of literature that, the lesions above the mylohyoid muscle with dimensions less than $6 \mathrm{~cm}$ in diameter were approached intraorally and lesions below the mylohyoid muscles with dimensions more than $6 \mathrm{~cm}$ in diameter were removed by extraoral approach $^{[16,17]}$. Furthermore, marsupialization had also been documented as an alternative treatment in cases of large cysts ${ }^{[18]}$.
Multiple studies which used extra oral approach reported that, the risk of intraoral approach for surgical enucleation of dermoid cysts especially in which extended beyond the mylohyoid muscle might be included; the injuries of submandibular and sublingual salivary gland ducts which could compromise salivary flow in addition to injuries of the lingual nerves ${ }^{[19,20]}$.

In the present study, all lesions diameters were equal or larger than $6 \mathrm{~cm}$ and extended through mylohyoid muscles operated through the intraoral approach. Postoperative assessment of salivary flow, pain, trismus, swelling, and nerve affection were reported and statistically analyzed.

Our results revealed that no affection of the previous parameters as well as the intraoral approach superior of extra-oral approach in case of avoiding cosmetic problems of the latter approach. Finally, the present study had been proved that, with the meticulous blunt dissection and retraction, the risk of intraoral approach for surgical enucleation of large sublingual dermoid cysts is considered successful safe and minimally invasive maneuver.

Conclusion: For the excision of large sublingual dermoid cysts, the intraoral sublingual approach could be used safely to access and excise these lesions regarding clinical outcomes.

\section{CONFLICT OF INTEREST}

The authors declare no conflict of interest.

\section{REFERENCES}

1. Brunet-Garcia A, Lucena-Rivero ED, Brunet-Garcia L, Faubel - Serra M. Cystic 
mass of the floor of the mouth. J Clin Exp Dent. 2018; 10: e287 - 90.

2. Turetschek K, Hospodka H, Steiner E. Case report: epidermoid cyst of the floor of the mouth: diagnostic imaging by sonography, computed tomography, and magnetic resonance imaging. $\mathrm{Br}$ J Radiol. 1995; 68 (806): 205 - 207.

3. De Ponte FS, Brunelli A, Marchetti E, Bottini DJ. Sublingual epidermoid cyst. J Craniofacial Surg. 2002; 13 (2): $308-310$.

4. Puricelli, E., Barreiro, B. O. B., Quevedo, A. S., and Ponzoni, D. Occurrence of dermoid cyst on the floor of the mouth: the importance of differential diagnosis in pediatric patients. Journal of Applied Oral Science, 2017; 25 (3), $341-345$.

5. Koca H, Secking T, Sipahi A, Kazanc A. Epidermoid cyst in the floor of the mouth: report of a case. Quintessence Int. $2007 ; 38$ (6): $473-477$.

6. Han, H. H., Ju, R. K., Seo, B. F., Moon, S.-H., Oh, D. Y., Ahn, S. T., \& Rhie, J. W. Dermoid Cyst Enucleation under Müller Muscle in a Patient with Blepharoptosis. Archives of Plastic Surgery. 2014; 41 (5): 607 - 609.

7. Nigam JS, Bharti JN, Nair V, Gargade CB, Deshpande AH, Dey B, et al. Epidermal Cysts: A Clinicopathological Analysis with Emphasis on Unusual Findings. Int $\mathbf{J}$ Trichology. 2017; 9: 108 - 12.

8. Bitar MA, Kumar S. Plunging congenital epidermoid cyst of the oral cavity. Eur Arch Otorhinolaryngol. 2003; 260 (4): 223 - 225.

9. Shigeyuki Fujita, et al: A case report of a long-term abandoned torn lingual nerve injury repaired by collagen nerve graft induced by lower third molar extractionMaxillofacial Plastic and Reconstructive Surgery volume 41, Article number: 60 (2019).

10. Iseri M, Ucar S, Ozturk M, et al. Dermoid cysts of the floor of the mouth: a review. J Otolaryngol ENT Res. 2015; 2 (3): $106-109$.
11. MacNeil SD, Moxham JP. Review of floor of mouth dysontogenic cysts. Ann Otol Rhinol Laryngol. 2010; 119 (3): 165 - 173.

12. Lee, M., Lee, C., Sim, C. and Nagadia, R. Sublingual dermoid cyst: Case report and a review of the clinical, radiological and histological aspects of this rare condition. Oral Surg, 2018, 11: $307-152$.

13. Hemaraju N, Nanda SK, Mediker SB: Sublingual dermoid cyst. Indian Journal of Otolaryngology and Head and Neck Surgery 2004; 3: 218 - 220.

14. Bhalla S, Acharya V, Ally $\mathrm{M}$, et al Acute presentation of an intraoral dermoid cyst causing airway compromise in a young child BMJ Case Reports CP 2019; 12: e228421.

15. Kandogan T, Koc M, Vardar E, Selek E, Sezgin O: Sublingual epidermoid cyst: a case report. J Med Case Reports 2007, 1: 87.

16. Bommaji SB, Qureshi MY, Reddy G S, Rampati S. Submental dermoid cyst mimicking double chin. Niger J Surg 2019; 25: 217 - 9.

17. El-Hakim IE, Alyamani A Alternative surgical approaches for enucleation of dermoid cyst of the floor of mouth. Int $\mathrm{J}$ Oral Maxillofac Surg. 2008; 37: 497 - 499.

18. Eken M, Evren C, Sanli A, Bozkurt Z . An alternative surgical approach for sublingual dermoid cysts: A case report. Journal of Ear, Nose and Throat. 2007; 17: 176.

19. Kinzer S, Mattern D, Ridder GJ .Diagnostic and therapeutic management of a big cyst at the floor of the mouth--a case report. Laryngorhinootologie. 2006; 85: 827 - 831 .

20. Elarbi MS, Alshawish $\mathrm{H}$, Khalifa O .Large Sublingual Dermoid Cyst in the Floor of Mouth and Submental Space. Otolaryngol (Sunnyvale). 2017; 7: 287. 